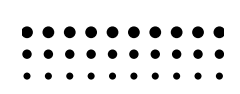

\title{
Core Components of Dilemma Actions
}

Co, the million-dollar questions are these: When are dilemma actions effective? Why? And what is the process behind designing a successful one? How do we measure efficacy? Is success only measured by the fall of a dictator? Or are there other ways to gauge success?

A core component of the tactics of dilemma actions is that they teach activists engaged in nonviolent struggles for democracy to think in ways that will allow them to succeed. Repressive regimes are successful, in large part, because they convince the population that they don't have alternatives and they don't have enough power to effect change. But our research on dilemma actions-and my personal history of training hundreds of activists worldwide in how to design them-proves that they do offer a path to systemic change. Planning dilemma actions shows activists how to use the 
hypocrisy, abuses of power, and intolerance of repressive leaders against them. Dilemma actions destabilize repression not just by revealing injustice and excess, but also by mocking the oppressor and showing its weaknesses-and ultimately undermining its authority. In other words, it's not only about inspiration and creativity, but about a process.

It is already clear that dilemma actions place an opponent in a situation where any response results in a humiliating outcome. In the designing process, nonviolent strategists clearly attempt to create a lose-lose framework for their opponent.

According to the CANVAS Core Curriculum and other literature, there are three core components of a good dilemma action.

\section{Create or Identify a Rallying Issue Meaningful to the Public}

$A_{\text {that success in any of their manifestations requires }}^{\text {ctivists who have written about dilemma actions know }}$ paying attention to several critical elements. You have to know how the repressive power works, and you have to be savvy about winning hearts and minds.

You need to wisely choose the target of the dilemma action-that is, the beliefs and policies that the action will address. Both anecdotal evidence and research show that the most effective issues are usually related to government 
prohibitions or policies that intrude into people's personal lives, like the fact that citizens need salt and they don't want their government to regulate it. So, the first step in designing a dilemma action is to review the opponent's policies for burdensome restrictions on people's day-to-day activities. The more personal and intrusive those restrictions are, the bigger the dilemma will be for the opponent. This "review" doesn't mean spending hours in the library's basement archives or performing deep investigative journalism. Shadowy revelations are not the sort of policy we're looking for here. We mean the big, obvious, slap-in-the-face affronts, the ones that are already under everyone's noses. Create a shortlist of those.

Then, sort through them for the policies that run counter to widely held beliefs, even among the opponent's supporters. Think, for example, of the simplicity of refusing to give up your seat on a bus. When Rosa Parks chose to do that, she easily called attention to the outrage of segregationist policy.

\section{Design the Action}

dentify an action that will put the opponent in a position Lof either granting the nonviolent movement an exemption to the restrictions or engaging in unpopular sanctions. As with any successful nonviolent tactic, your dilemma action plan should minimize risks and boost possible benefits within your specific social, cultural, religious, and media 
environment. In one of the most comprehensive academic analyses to date, "The Dilemma Action: Analysis of an Activist Technique," Majken Jul Sørensen and Brian Martin identify five factors common to dilemma actions that have forced opponents into a tough spot, thus representing a "todo list" for designing dilemma actions ${ }^{15}$ :

1. The action needs a constructive, positive element, such as delivering humanitarian aid.

2. Activists should use surprise or unpredictability, such as staging a protest with holograms instead of live people.

3. Opponents' prime choices should be in different domains (political, social, personal), which means that the choices are difficult to compare. When a police officer has to choose whether or not to arrest a nonviolent protester at a demonstration doing something funny and popular, for example, there is a conflict between the economic (keep the job) and the social (agree with the protester) domains.

4. Dilemma actions should seek a timing that appeals to mass media coverage, making it difficult for authorities to ignore, such as including an element of humor or a prank the way that the Yes Men did when they impersonated Dow Chemical, which makes it fun for media to cover.

5. Appealing to widely held beliefs increases pressure, such as appealing to society's basic idea that governments shouldn't tell you that you can't wear a particular type of hat. 
Additionally, there are dilemma actions that backfire, and understanding what makes them backfire is essential. Our research shows that some dilemma actions can also divide audiences and cause backlash for the group by alienating potential supporters. Think of the well-known "Punk Prayer" performed by Russian dissident band Pussy Riot on February 12, 2012, in Moscow's Church of Christ the Savior. On one hand, it resulted in a lot of visibility and a sought-after, outsized response from the opponent; it also leveraged the widely held belief (even in very conservative societies) that religious institutions should function apart from the state and its party politics. Yet on the other hand, because Pussy Riot decided to perform their political action inside an actual church building, it was easy for their opponent to label their provocation as "anti-religious" and "insulting to those who believe." This made it easy for the target of Pussy Riot's actions to stoke nationwide outrage against the punk band. So as in the example of how the national anthem kneeling protests of NFL players led to debates about signaling patriotism rather than police brutality, the Pussy Riot protest similarly led to an uproar over their disrespect for religion rather than a desired debate on the role of religious institutions in politics and society. This blowback underscores why it is essential to carefully plan and design each aspect of the dilemma action in order to measure its potential impact and possible interpretations. 
The best way to avoid blowback is to have a strong sense of the various examples of dilemma actions and their outcomes. While we share a selection of dilemma actions throughout this essay, there are many more examples to draw from. The best way to ensure that your dilemma action will be successful is to study similar examples so you can compare them to your specific context and gauge the fit. For a good resource on dilemma actions, we recommend Beautiful Trouble: A Toolbox for Revolution, a collaborative effort edited by Andrew Boyd and Dave Oswald Mitchell that brings together dozens of seasoned artists and activists from around the world to distill their best practices of "decision dilemmas" into a toolbox for creative action. Published first in 2016, it is also a website that is constantly updated with new examples of case studies, principles, tactics, practitioners, and theory. ${ }^{16}$

If you want even more ideas, you can also look at the "Global Nonviolent Action Database," which offers free access to hundreds of completed examples of nonviolent action. ${ }^{17}$ All of this work by activists offers inspiration as you think about how best to devise a struggle for democracy. We may have slightly different tactics we emphasize, but all theories of dilemma actions have a common thread: force the government to be stuck in a dilemma where if they do nothing to stop the protesters, they look bad, and if they do something to stop them, they look even worse. 


\section{Perform the Action and Benefit from Its Outcome}

Tf you've been savvy about Steps 1 and 2, you will prob1 ably have selected some very unpopular individualsstakeholders and "public faces" of unpopular restrictions, policies, or practices within the oppressive system-who personalize the dilemma action. That means the opponent is likely to react, and if that reaction is strong enough, it will undermine your opponent's legitimacy.

While it is best to identify a public figure who embodies what you are resisting, it is also wise to add celebrities to your ranks if you can. When actors, sports personalities, thought leaders, or local community leaders participate in the action, they raise its profile and thus directly influence its outcome. People identify with role models, and if these personalities show up, many more people will usually follow.

We tried it ourselves in Serbia. A famous Serbian actor, Voja Brajović, finished a very popular performance in the Serbian National Theatre in late 1999. For this performance, he replaced his usual shirt with a T-shirt with the fist symbol of the Otpor movement, handed to him earlier by Otpor activists. Wearing this symbol in public was strictly prohibited, and average activists-even including high school kids-were regularly detained for wearing it. But when a public figure like Brajović wore the symbol, the police were 
too confused to interrupt the show, and arresting one of the most prominent actors in Serbia on the stage would have been too costly even for Miloševićs regime. Days later, actors and musicians repeated this action all over Serbia, setting brave personal examples for average citizens who wereuntil then-regularly arrested for wearing this symbol in public and therefore afraid to take risks. Creative and wellplanned action increases the costs of intervention for your opponent and reduces the risks and costs of disobedience for ordinary people.

Once a dilemma action is performed, many of the groups in our study added another step. This follow-up step, which we commonly described in my Otpor days as "postproduction of the tactic," aims not only to build on the immediate outcome, but also to exploit the opponent's response to the action by gaining as many press mentions, views, and new supporters as possible. There is a range of ways to draw attention to a successful action and use it to build your ranks, but the most important one is to make sure that the media's coverage of your story continues. For instance, have your own Twitter army keep using a hashtag or form connections with recognized journalists. Activating this step means having a follow-up media plan before you begin your action.

The goal is always to encourage more people to support the nonviolent movement. Bigger numbers help you. As you draw attention to your action-showing the public how you put your opponent in a dilemma in a peaceful and socially 
supportive way-you help show that your vision is not a radical threat to society, but, rather, that your target is the real threat. More people will join your struggle. And, of course, as the next section explains, one excellent way to win people's hearts and minds is to add the component of humor to your dilemma action, because the media can't resist covering stories where those in power are made to look silly or stupid. 